\title{
THE PLANNED LEGAL REGULATION OF THE EU'S POST-2020 DEVELOPMENT POLICY - OR AN ASSASSINATION AGAINST THE COUNTRYSIDE
}

\author{
István Finta ${ }^{1}$
}

Received 2 October 2018; Accepted 17 October 2018

\begin{abstract}
The European Union is a representative and guardian of fundamental values that secure the guarantees of the democratic functioning of the Member States. One of the core values of the European Union and of democracy is the rule of law, which includes, inter alia, the compliance of any interference with the law and the primacy of higher laws. The basic question is whether these core values are binding on the EU legislator itself as well? In this context, further questions can be raised such as whether the territorial approach inherent in Article 174 of the Treaty, which is the basis of the European Union's operation, to what extent it prevails in EU law? How the countryside, as a territorial unit deserving particular attention, does appear in legislation and in EU development policy? Does the legislator strive to enforce the fundamental goals set out in the Treaty - such as strengthening cohesion, mitigating territorial differences? The paper seeks to address these issues primarily on the basis of an assessment of the EU draft legislation for the post-2020 period.
\end{abstract}

Keywords: cohesion, territorial approach, rural development, regional development, development policy

\section{Introduction}

The subject of this discussion paper differs considerably from studies because it is not intended to provide a wide-ranging description of the literature, and it is not, in particular, intended to capture dogmatic findings that seem to be irrefutable. It focuses not on evaluating previous scientific results, but on critical reviews of future proposals. In style, instead of the restrained, balanced findings, it is often characterized by provocative, sometimes crucified, questions that are precisely designed to put the critical problems in the spotlight and not to offer the opportunity to overcome fundamental issues and problems. This does not mean that the findings and the questionnaires would lack a scientific basis, or could not be substantiated with adequate data. However, the goal is constructivism, where possible answers may be connected to the questions.

This paper is focused on the spatial view of the Community legislation, on the emergence of certain types of regions - especially rural areas - and on the handling of complex solutions for complex issues, and the opinions of them.

\footnotetext{
${ }^{1}$ István Finta, Ph.D., Hungarian Academy of Sciences, Centre for Regional Studies, Transdanubian Research Institute Pécs; e-mail: finta@rkk.hu. ORCID: 0000-0001-6916-7325
} 


\section{The legal basis for development policy interventions, the European Union's development objectives}

Today, the legal basis for the Union's development policy intervention and the goals for interventions can be considered as evidence, but in the light of the post-2020 draft legislation, the question arises as to whether the development policy at Community level is indeed geared towards these goals and, accordingly, is the intervention that is laid down in the draft legislation at Community level are in accordance with the law.

The Treaty on European Union, which can be considered as a baseline, sets a number of goals, but targets - for development policy - form a logically structured, hierarchical system of objectives.

At the top of the hierarchy is Article 174 of the Treaty, which, although all legal texts are quoted in the introductory part, but the mere quotation of letters and sentences does not necessarily mean that they reflect its content and spirit, and that the supreme goals genuinely conform to the additional objectives standing on the lower levels of the target hierarchy.

For the sake of accuracy and misunderstanding, it is appropriate to quote Article 174:

\section{„Article 174}

(ex Article 158 TEC)

In order to promote its overall harmonious development, the Union shall develop and pursue its actions leading to the strengthening of its economic, social and territorial cohesion.

In particular, the Union shall aim at mitigating disparities between the levels of development of the various regions and the backwardness of the least favoured regions.

Among the regions concerned, particular attention shall be paid to rural areas, areas affected by industrial transition, and regions which suffer from severe and permanent natural or demographic handicaps such as the northernmost regions with very low population density and island, crossborder and mountain regions."

Although it is clear from the legal provisions, it is advisable to highlight some of the articles in the regulation, in order to evaluate consistency with other goals:

- The fundamental objective is to reduce regional disparities and inequalities. To this end, it cannot be explained, at any other point (e.g. enhancing competitiveness), to support interventions that not only reduce territorial differences, but also increase richer regions and make "poor" poorer.

- The Treaty is thinking about space rather than preferring sectors. (One-sided sectoral development always poses a risk that national economies dependent on some sectors may - in the event of a crisis - cause serious emergencies.)

- The Treaty specifically names certain territorial units for which further objectives and interventions are needed.

\section{Relationship between the priority territorial units and the objectives defined in the Treaty}

The Treaty explicitly names rural areas as territorial units that need to be monitored separately, for the progress of territorial differences. Monitoring should also include obviously adequate for intervention purposes, sources, indicators, and methods, but in the absence of these, monitoring would be merely passive, which, of course, is not in line with the equalization objectives in Article 174 , which presuppose an active activity and concrete interventions.

Adequate interventions can be in line with the characteristics of rural areas, which are associated with characteristics such as population migration, aging, depopulation, overall unfavourable demographic trends, segregation, low educational attainment of the population, lack of enterprises from the national average, the low level of secondary and tertiary sectors, the accessibility problems of a wide range of public services, the healthy environment, natural 
resources, peculiarities, the possible base for healthy food production, the depositary of the cultural heritage of the countryside, etc.

For any Member State, it is quantifiable that the degree of development of rural areas is more or less, but certainly below urban, metropolitan areas.

There is only one - but indisputably important - indicator on Hungary, which illustrates both the differences and the processes between rural and non-rural areas (Figure 1).

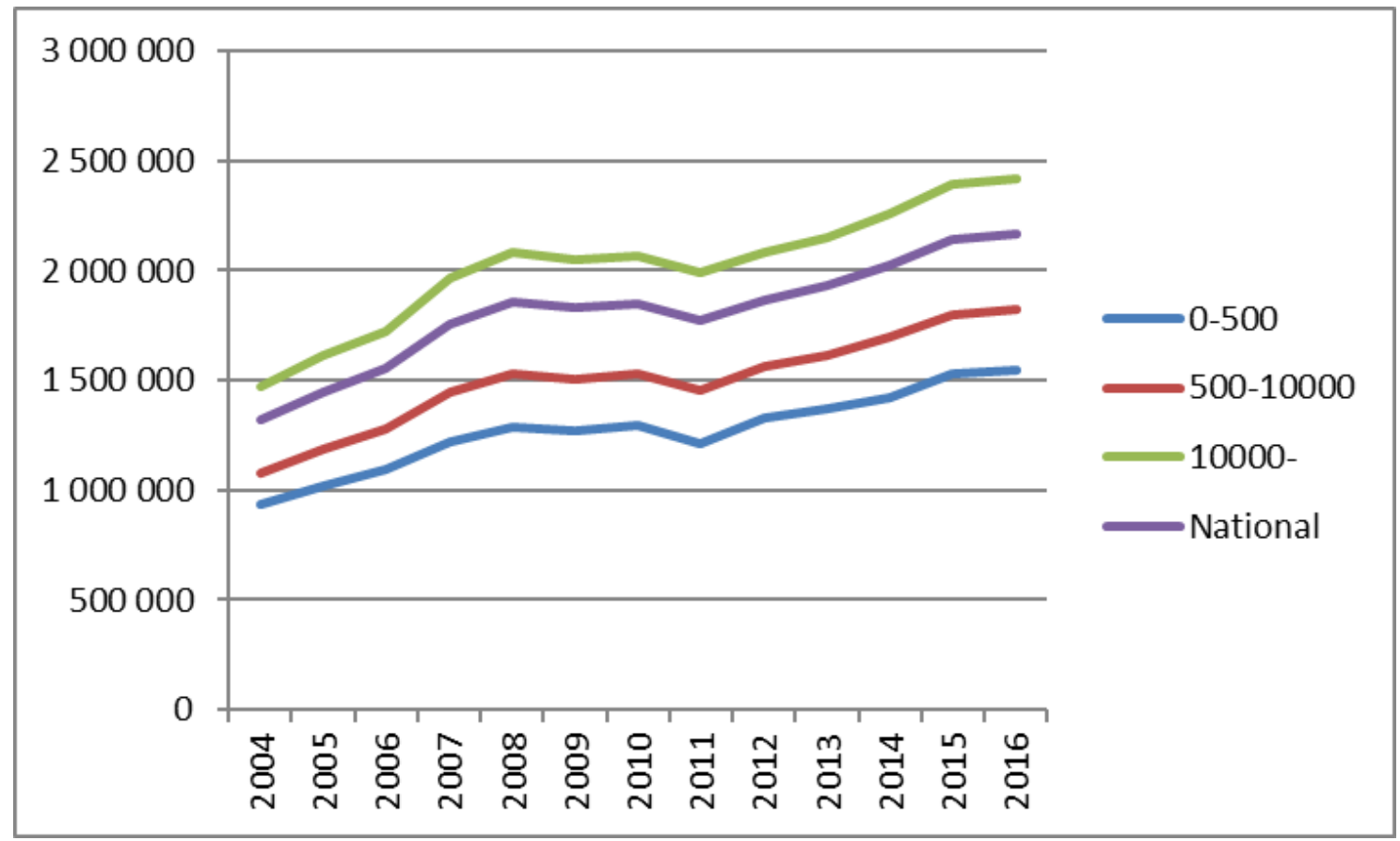

Fig 1. Taxable income by settlement size, at current prices. Source: the author's own edition on the basis of Central Statistical Office data

On the one hand, Figure 1 well illustrates the income differences of settlements with less than 10,000 inhabitants - according to the Hungarian standards, these are the geographical areas of rural development intervention - between the national average and non-rural areas. It also appears that there is neither divergence nor convergence between them, unfortunately. The latter may be important in the context of the fact that it clearly contradicts the finding that Hungary has already significantly closed up to the EU's GDP average and to the more developed Western European states. If we only look at the averages that the global investment of the capital and some major cities - Mercedes - distorted, then the claim - at a national scale - may be true. However, in the case of rural areas that make up most of Hungary, there has been no realistic catching up, and even in a number of very important indicators - population, public services the difference significantly increased.

The content of Article 174 is considered to be justified, according to which rural and urban areas are not considered to be the same for development, and rural areas deserve particular attention.

The question is how far the legislative regulation transposing the development policy is to respond to these differences, how and to what extent it is sensitive to the problems of the countryside, how does it intend to promote the exploitation of development opportunities?

In order to answer the questions, it is necessary to examine the system of objectives, sources of each fund, with the development methods offered and the indicator system that justifies the actual or anticipated impact. 


\section{European Regional Development Fund (ERDF)}

\section{The place and role of the countryside in the ERDF regulation}

Firstly, the regulatory proposal for the European Regional Development Fund for the period after 2020 should be evaluated, as Article 176 of the Lisbon Treaty says "The European Regional Development Fund is intended to help to redress the main regional imbalances in the Union through participation in the development and structural adjustment of regions whose development is lagging behind and in the conversion of declining industrial regions."

The draft legislation on the ERDF Regulation confirms the objective of the Treaty (remedying inequalities), which was supported by the results of the social consultation presented in the proposal, where the former opinion ranked first in mitigating inequalities. On the basis of these, it would be reasonable to expect that the ERDF regulation will deal with rural areas according to their weight. According to Article (1) of the proposal „ERDF is to contribute to mitigating disparities between the levels of development of the various regions and to mitigating the backwardness of the least favoured regions, among which particular attention is to be paid to regions which suffer from severe and permanent natural or demographic handicaps such as the northernmost regions with very low population density and island, cross-border and mountain regions."

Thus, the Fund of which main task is managing inequalities - unlike the provisions laid down in the Treaty (Articles 174-175) - due to some reason, which is not justified and not explained, excludes rural areas completely out of the list, mainly out of the whole regulation.

If we look at the countryside in general as a possible intervention area in the regulation, then we cannot get much result. Secondly, two of the two solutions to the Fifth Policy Objective of the Regulation, there is still a potential element of the "inter alia" rural area as an integrated spatial development approach, but if we look at more detailed provisions for integrated development, (Articles 8-9) Integrated intervention solely controlled by the ERDF is directed at urban areas. This is called by the Decree as sustainable urban development, which requires $6 \%$ of ERDF resources to be allocated at Member State level.

It is necessary to point out that the methodology and institutional framework for integrated territorial development is defined by the Common Provisional Regulation (CPR), which is nothing more than a community-led local development (CLLD) for the former LEADER model. In the present context, therefore, an ERDF-funded and ERDF targeted urban CLLD programme, focusing on cities and a European Agricultural Fund for Rural Development (EAFRD) supported LEADER (EAFRD) programme funded instrument seem to be elaborated. If an enthusiastic seeker wants to find the mechanisms that would include the guarantees, comprehensive, or detailed rules of effective cooperation between the various instruments supported by the various funds, he would be disappointed because these provisions have no trace of either in the individual fund regulations, and perhaps what is much more of a problem, even in CPR that should establish common regulations. (Of course, it is not acceptable that, within the framework of shared management, these rules should be set up by the Member States. If the basic conditions and the basic mechanism of possible co-operation are not set at Community level, there is no chance of solving this at Member State level, among others because of the differing detailed rules and indicators of the funds, etc.).

If we look for rural indicators, or maybe a resource allocation in the ERDF regulation, it may prove to be in vain. (If the countryside does not even appear at the level of targets - as a territorial unit to which special attention should be paid - it cannot be included in the additional content provisions.)

\section{Lack of thinking in space and in territorial unity, territorial vs. sectoral development}

In the case of the territorial units that require special attention and named in the Treaty, there is no doubt about thinking in space. When the fundamental objective is to reduce disparities between territorial units, it is also desirable to think in appropriate territorial units. The question is whether, when we compare the objectives of the basic objective and the ERDF regulation, if there 
is a causal link between them, are the ERDF objectives a harmonious system with the overall objective that otherwise provides the EU's legal basis for intervention.

The draft Community legislation for the post-2020 period is at least two tiers (in this aspect, it does not differ from the target system for the 2014-2020 period). The so-called policy objectives were set at the level of the Common Provisional Regulation (CPR), while its further details are set out in the Fund Regulations. In the case of the ERDF, twenty-one further five policy-related objectives, or so-called specific objectives have been defined.

The Community's decision-maker may consider the first two policy objectives to be the most important as it sets out the ratio of mandatory resources to be used for these purposes. However, these goals are not related to space or territorial units (such as the countryside), but are more closely related to one or more sectors. For example, if the first policy objective - which is "smarter Europe by promoting an innovative and intelligent economic transformation" - is the first goal of strengthening research and innovation capacities and evaluating the introduction of advanced technologies, it is more related to, for example, IT sector than any other territorial unit. But the same thing can be said about the digitalization objective or the support of skills development related to industrial restructuring.

Why can it be a problem that the ERDF is unable to think in space but instead it chooses sectoral or sectoral type objectives that suits her own taste?

The preference of the sectoral or the tensile sectoral components of the economy, may involve dangers, especially over a relatively long period of seven years, when it may turn out that it is not necessarily the sector that provides the European economic space with the strengthening of world economic positions. It is not a question that e.g., digitalization is a pledge of development everywhere. However, it is a question of whether, for example, a high-tech digital centre in a capital city contributes to the socio-economic convergence of a small village of $300 \mathrm{~km}$ or so of a similarly developed region in the capital. This question - and along with the answer - is missing from sector-developed logic. Sectoral development policy, as it has been verified by empirical studies, is blind in space. This means, more specifically, that sectoral subsidies do not take into account territorial features or market positions. They favour the applicant who is more capable of meeting the employment, return, higher technology levels requirements, etc. In a competition of meeting these requirements, a metropolitan company starts off from a different position than a business in a peripheral area. The presence of different positions and available conditions of life in other areas of life (e.g. education) is the same. There is no doubt that sectoral development policies can include aspects that benefit less developed areas, but their practical impact is more than negligible rather than sufficient. Against this background, a development policy that reflects on spatial and territorial unity focuses on a given territorial unit (e.g. NUTS III, LAU 1), where players with similar capabilities compete for support resources, thus eliminating the fact that the more favoured and advanced the actors of the region would take away the development resources and opportunities for development.

If sectoral development policy is dominant, spatial thinking, and more specifically territorial and rural development policy, is more likely to merely be present as a set of scenarios. It may be because the development funds provided by the EU funds are concentrated in developed areas, leading to making the development of developed regions even more advanced, and making the underdeveloped areas, even less developed. The spatial disparities in allocating resources is well illustrated by the graph of Hungary's 2007-2013 programming period (Figure 2). 


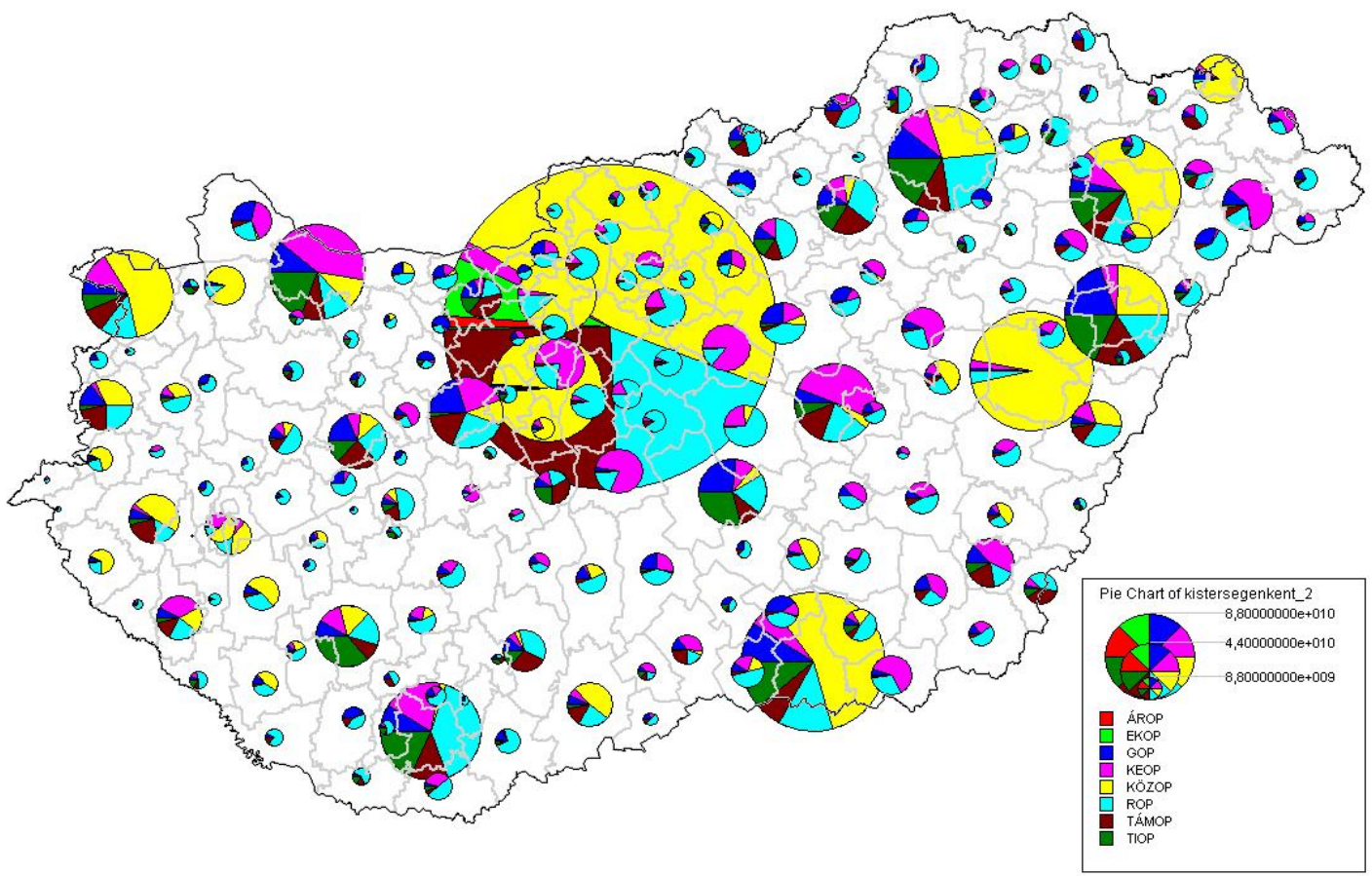

Fig 2. The distribution of application amounts per micro-region, broken down by operational programmes (as of year 2015)2. Source: the author's own edition on the basis of the database provided by the Prime Minister's Office

There is a territorial classification at county level (LAU level 1) in Hungary, according to the level of development of each territorial unit. For example, Figure 5 shows that the largest sources were allocated to the developed, i.e. the non-beneficiary regions.

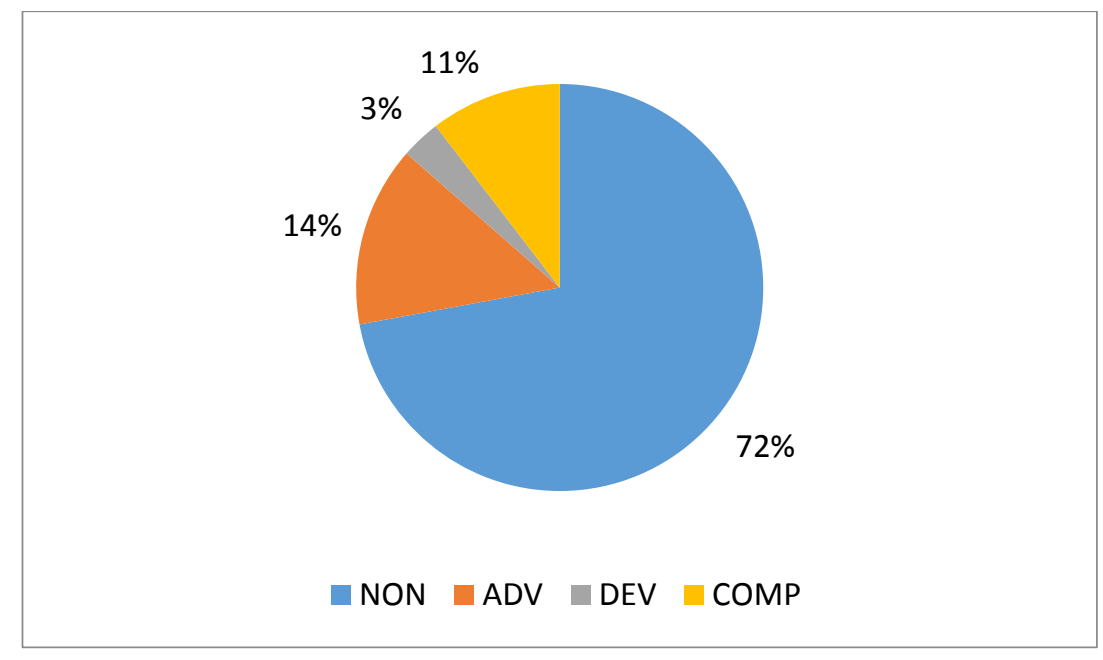

Fig 3. Total sum of subsidization broken down by (LAU 1) nomenclature ${ }^{3}$, thousand HUF (as of year 2015). Source: the author's own edition on the basis of the database provided by the Prime Minister's Office

\footnotetext{
2 ÁROP: State Administrative Reform Operational Program

EKOP: Electronic Administration Operational Program

GOP: Economic Development Operational Program

KEOP: Environment and Energy Operational Program

KÖZOP: transport operational program

ROP: Regional Operational Program

TÁMOP: Social Renewal Operational Program

TIOP: Social Infrastructure Operational Program

${ }^{3} \mathrm{NON}$ : non-beneficiary district; ADV: beneficiary district; DEV: district in need of improvement; COMP: district in need of improvement by a complex programme
} 
The - very sketchy, almost incomplete - presentation of the fundamentally different territorial effects of sectoral and territorial development policy seems reasonable in order to make their different, or even often conflicting, effects on territorial development perceptible.

Returning to the ERDF's support philosophy and its target system, it can be stated that, if the sectoral developments are to be preferred at Community level, the consequences are not at all in line with the objectives set out in the Treaty for which this fund was established (the ERDF funds will not reduce, but rather may even increase spatial disparities within Member States).

The legislators of the ERDF Regulation reduced regional development for integrated development. Integrated development is of course an excellent method, but the available resources (6\% of the total ERDF framework) are extremely disproportionate compared to sectoral development sources. It is commonly argued that this $6 \%$ is only a mandatory minimum, and that Member States may change it and may set a much higher rate. The passage of such a decision to the Member States cannot be accepted because the Community level is responsible for achieving the objectives set out in the Treaty, and not the Member State in the area of EU jurisdiction. If the ERDF target system, the defined methods and sources of funding are insufficiently serving the objectives set out in the Treaty, it is the responsibility of the Community level, not of the Member State. If the Treaty is thinking in territorial units and it wants to promote their cohesion, the question is whether the ERDF regulation legislator has been the power to think in the sphere of sectoral development instead of territorial approach, the effects of which may be contrary to the objectives set out in the Treaty?

\section{European Agricultural Guarantee Fund / European Agricultural Fund for Rural Development (EAGF / EAFRD)}

It should be noted at the outset that the regulation of two Funds (European Agricultural Guarantee Fund - EAGF, and the European Agricultural Fund for Rural Development - EAFRD), having a decisive role in implementing the objectives of the common agricultural policy (CAP), in a regulation, the ambition of programming the EAGF - is a revolutionary change from legislative viewpoint as well. It is known that EAGF funds allocating a major part of CAP resources are basically intended to finance running costs while the EAFRD has a relatively small framework to promote development goals.

It is also known that Article 175 of the Treaty provides for the so-called EAGGF Guidance Section, which is currently compatible with the EAFRD Fund, to contribute to the objectives set out in Article 174 (mitigation of territorial differences, highlighting certain spatial categories, such as rural areas). It is a question of how a legislative product presenting many innovations fulfils or how it can overcome this obligation.

Although the regulation generally refers to the Treaty - which makes it possible to create it at all - but we would look for Articles 174-175 in vain in the document because the legislator, refers to Articles 42-43 instead of as an authorizing provision, which includes the possibility of forming a common agricultural policy. The question then is how the countryside is at all appearing in the regulation, and how far the regulation can be considered as an exclusive sector policy instrument serving the interests of a single sector, the agricultural sector.

In the first part of the document, which can be considered as a reasoning and an explanation, the countryside is merely the subject of food supply, where the subjects of subsidization can almost exclusively be agricultural entrepreneurs - under certain conditions. It is typical that for example, while the reasoning deals with wines through several paragraphs - within the agricultural sector and in the food sector, from this part the issues of non-agricultural population, society, economy and culture of the countryside are all excluded.

The legislator's and the EAGGF / EAFRD Regulation's attitude to the countryside may most clearly be demonstrated by Article (16) of the introductory provision of Cork 2.0 Declaration, highlighting the lack of attractive employment opportunities and professionals in rural areas, networks, infrastructures and the neglect of investment in basic services, the emigration of young people, and then setting up the goal of strengthening the socio-economic structure of these areas. The continuation - that is, legislative solutions - most closely reflects the narrow-minded, only 
one-sector-based approach that addresses the so-called " Rural Development Fund, offers opportunities within the framework of bio-economy, circular economy and ecotourism. It is worth noting now that the "solution options" indicated in the agrarian sector can secure livelihood only for a very small number of rural people. If we add to this, the continuing decline in the number of people employed in agriculture, then the "answers" of the country's wide-ranging questions do not even reach the threshold of valuation possibilities. However, before a comprehensive assessment of the CAP's impact on rural areas, it is necessary to examine the target system which, at least in its name, is responsible for European agriculture and rural development. (Let us ignore now that the English term means agricultural development as rural development. The goals of the fund have been focusing not only on the agrarian sector for several decades).

The EMGA / EAFRD Regulation target system can be considered on three levels at least. It is a special feature that, as opposed to the regulatory practice of the 2014-2020 programming period, it has been excluded from the scope of the Common Provisions of the Union's development policy (CPR). This fact seems to have authorized the drafters of the regulation to set up a self-contained, life-independent target system that does not need to be linked to the general overall objectives. (Of course, on paper and at the level of the operational programmes of the Member States, such links and fictitious synergies can be produced at any time, which cannot, appear in reality, or if they can, it is just a special exception.)

The general objectives of the Regulation are as follows:

- promoting an intelligent, resilient and diversified agricultural sector guaranteeing food security;

- promoting environmental protection and climate policy actions and contributing to meeting the Union's environmental and climate objectives;

- strengthening the socio-economic structure of rural areas.

The first two elements are explicitly a sectoral or environmental issue, while the last general objective may be a source of hope, and it is a question of whether this goal is reflected in the lower levels of target hierarchy.

Article 6 of the specific objectives includes only one of the nine objectives that address not only agricultural issues, but that is also the case with the agricultural sector: "promoting employment, growth, social inclusion and local development in rural areas, including bio-economy and sustainable forest management ".

The change in proportions is clear, but it still seems possible to reach the overall goals of rural areas at further stages of the regulation's target system.

The third level of the development objective is contained in Article 64 of Chapter IV "Types of interventions for rural development". Here the following interventions are listed:

- climate protection and other management commitments;

- disadvantageous natural resources or other area-specific disadvantages;

- area-specific disadvantages resulting from certain mandatory requirements;

- investments;

- start-up activities of young farmers and start-ups in rural areas;

- instruments for risk management;

- cooperation;

- exchange of knowledge and information.

If we want to see the socio-economic structure of rural areas at the level of specific interventions, our chances are zero. Rural areas, at least in this context, have been extinct and have been deserted (for the time being) from the intervention target system. 
The name of the interventions already refers to their contents, which, in line with higher level goals, are related to agriculture and to the environment and climate change. It can be anticipated that "knowledge exchange and information" are also limited to agricultural activity.

However, in the case of "investment" interventions, there is a chance for non-sectoral interventions, since it is possible to apply a higher rate of support for the development of basic services in rural areas. This intervention refers back to Article 6, where one of the nine objectives is not limited to rural areas. Thus, at the level of interventions, if not directly, but at least indirectly, there is a goal within which even basic service development can be implemented. (For the sake of fact, it is also important to note that this can only be achieved if a Member State incorporates it into its programme and allocates resources to it. Neither incorporation nor source allocation is mandatory, as this already falls into the competence of the Member States but it clearly shows the likelihood of the intervention and its potential impacts on decreasing agricultural resources and the targets focusing in $95 \%$ rate on agriculture.)

Interventions include "cooperation". Co-operation refers here to cooperation within the agricultural sector, with the exception of the LEADER program, which alone offers the opportunity to provide complex answers to the comprehensive questions of the countryside within the whole regulation. In this regard, two remarks should be made here:

- It goes without saying that $5 \%$ of the (declining) EAFRD framework does not provide sufficient coverage for the complex problems and opportunities of the countryside (the findings concerning ERFA CLLD resources for the mandatory minimum Commission protection are still valid here).

- The "concealment" of LEADER, exacerbating it from the level of interventions constitutes a serious breach in the Union's rural development policy, and at the same time it expresses the changed approach aiming at narrowing the scope of common agricultural policy to a single sector instead of the countryside.

Compared to the target system of the past programming periods, the post-2020 EAGF / EAFRD Regulation brings a breakthrough not only for the LEADER programme. During the 2007-2013 period, EAFRD organised its targets around four so-called axes. The first two targets were specifically geared to the agricultural sector and the third was to promote rural development not primarily agricultural development, while LEADER formed a separate fourth axis.

During the 2014-2020 programming period, one (the sixth) of the six priorities addressed issues of social inclusion and poverty. The LEADER programme could also receive support under the sixth priority. The trend is, therefore, pointing to a decline to reach its peak in the post-2020 period and made possible for the sectoral approach of agricultural subsidies to ultimately win over complex rural development. This coercion can be regarded as at least as significant as the exodus of the Jews from Egypt in the Old Testament.

Perhaps, it requires not a great wisdom to see, that complex problems can only be solved by complex methods. Perhaps, it is also evident that no sectors, and no sector development systems alone, are capable of solving the problems of a territorial unit or area type. And if we look at the role of the agricultural sector in the preservation of the rural population, the provision of rural livelihoods, employment, and its trend, then the continuous decline is perceptible for all Member States. It is well known that improving the competitiveness of the agricultural sector and its continuous modernization requires less and less employees. If there are any such delusions often appearing under the SMART mask - which, even in the near future, will provide an opportunity for controlling a self-controlled land-ploughing tractor from a metropolitan centre, then there will be no need for people in rural areas for the agricultural sector at all. Unfortunately, the current approach goes in that direction, when developments are focusing on plants, animals, technology, and nutrition, and neglecting people, and more specifically, people living in the countryside. This "rural development" is just strengthening the emigration of rural population, the partial or complete disappearance of settlements, and the formation of segregated communities in the enclaves. In the medium term, the perspective of a food factory like rural countryside working without people can be visualized, where former village communities, village 
lifestyles and culture are lost in the darkness of the past, and at most can remain in the world of skansens as a reserve.

It is also a well-known argument that the CAP (and its instruments) alone cannot solve the problems of the countryside and rural development. According to this view, the CAP plays a complementary role in rural policy. The first statement can be explicitly understood as a single sector is just as inadequate to fully develop the countryside - or any territorial unit - as any expressly sector development policies are not suited to the rational development of any territorial unit. The statement of complementarity, which is otherwise referred to by the Regulation as a requirement for the Member States' CAP plans, (59), would be well founded if there was something to be supplemented. As it is seen, the ERDF does not deal with rural areas, and this territorial unit is not a focal area for other EU funds either. Thus, there is nothing to supplement with the CAP or the EAGF / EAFRD Regulation. (The countryside has been split between several chairs.) Such fragmentation of EU funds makes it impossible for the fulfilment of objectives and requirements set out in Article 174-175.

\section{Thinking in space in the practice of EMGA / EAFRD}

While in the case of the ERDF, there was a lack of thinking in space and territorial units, some territorial units appear in case of EMU / EAFRD. Such territorial units are NATURA2000 areas or disadvantaged areas. This approach connects space and territorial units exclusively to agriculture and to the agricultural sector. The features of man-made society - e.g.: small villages or larger population density, settlement-structured territorial units - are completely missing from the Regulation.

\section{Competitiveness vs. mitigating spatial disparities}

In the ERDF's sectoral development philosophy, the focus of competitiveness is in the foreground, as opposed to the mission that created this fund. This choice of value was most pronounced in relation to the choices made in relation to resources available to the Fund:

"ERDF: The policy option includes a 7\% reduction in the budget by:

Option 1: General Reduction.

Option 2: Reducing the amount of contribution to more developed regions.

Option 3: Maintaining support for key areas (thematic concentration) and mitigating other topics. "

The legislator selected the third option where key areas are tensile industries, which are typically located in developed regions. The second option is specifically territorial, where contributions could be maintained in less developed areas, while more developed areas could have gained a less amount of resources. This solution would have been closer to the primary mission which is to mitigate territorial differences.

However, the EAGF/EAFRD, whose main task is not to reduce disparities, represents the following philosophy:

"It is clear that the solution for redistributing a significant proportion of direct payments to lowproductivity holdings and regions will lead to a reduction in EU competitiveness in the short term, while also providing for a more effective protection of the environment" (Justification, explanation, p. 8.).

"It is appropriate that less developed regions, similarly to the current situation, should receive higher co-financing in the future; higher ratios will also apply to certain other interventions, such as payments made under LEADER or management commitments" (Justification, explanation, p. 10.).

Thus, the EAGF / EAFRD legislator therefore far more fulfils the objectives set out in the Treaty than the Fund for which it should have been a primary task. 


\section{Sources of rural development in the CAP system}

According to the trend of changes in rural development goals, it is not surprising that the resources are adjusted to changes in the development goals. While in the 2007-2013 period, in each Member State - although at different levels - the share of non-agricultural subsidies was well established and not negligible at all. In the 2014-2020 period, this was much less traceable and relevant. While between 2007-2013 in Hungary, for example, supporting the development of agricultural activities was around $80 \%$ of the total budget. In the period 2014-2020, the so-called" the promotion of agricultural activities has already appeared within the sixth priority, so it is not possible to distinguish between priorities for agricultural and non-agricultural development. One sure point is the LEADER program, of which at least $5 \%$ represents a complex support in which activities are not only or not primarily agricultural.

In light of the objectives of the EAGF / EAFRD for the post-2020 period, the $5 \%$ ratio of LEADER programme can also be considered as a safe point. (In any case, it is remarkable that the ERDF with far greater resources will provide $6 \%$ for the CLLD, operating with the same method as the LEADER programme, but EAFRD with fragmented development resources compared to the ERDF is providing a much smaller amount for less-favoured rural areas.)

\section{Indicators}

As far as the indicators are concerned, the EAGF / EAFRD Regulation is consistent and consistent with the fact that space and territorial units appear only in relation to that specific sector, i.e. agriculture. The proportion of indicators outside the agricultural sector is negligible, which also conveys the message that the interventions of the fund do not really expect an effect that may arise outside the agricultural economy.

(Out of the thirty-eight result indicators, only three can be considered as not specifically limited to the agricultural sector. The thirty-five output indicators linked to each intervention - refer to the activities that quantify the direct results generated by the activities - they could include more than one of the extracurricular developments, e.g., the number of subsidized local infrastructures and the number of rural entrepreneurs receiving activity support - however, the "investment" intervention, which may include non-agricultural output indicators, refers in a tricky way to the nine objectives set out in Article 6 that the investments are aimed at. Out of them, only one is not explicitly linked to the agricultural sector. Thus, only two of the 35 output indicators are not exclusively related to agricultural activity; they are the number of productive investments outside the subsidized economy and the number of selected local development strategies - LEADER.)

\section{Complexity}

The sectoral approach of the EAGF / EAFRD Regulation is unlikely to require any specific evidence. Perhaps, it is not necessary to prove separately that a single sector - agriculture - is unable to solve the problems of the countryside and, unfortunately, is less and less able to ensure the livelihood of the rural population. It is regrettable that the use of development instruments with a complex interest has only a support of $5 \%$ on the Community level. (It is even more regrettable that the professionals had to fight against the representatives of the extremely powerful agrarian lobby).

It is also a serious step backwards that the EAFRD is excluded from the scope of the Common Regulations (CPR). This step is so helpful for the approach of each of the funds, the development of a complex approach as the introduction of the EURO in a Member State that never meets the Maastricht convergence.

\section{European Social Fund (ESF)}

According to the introductory document to the 2020 ESF Regulation, "ESF+ promotes the development of a socially conscious Europe and contributes to economic, social and territorial cohesion in accordance with Article 174 TFEU, which is a necessary precondition for working properly and viable as an economic and political alliance, Union." 
The authorizing provision, which is the legal basis and the definition of the main purpose of the regulation, is therefore clearly outlined in the document. It is a question that the territorial units defined in Article 174 and, in general, the territorial viewpoint of how will they appear in the law.

The document summarizes the challenges that the ESF is about to address in some form:

- shortfalls in skill levels,

- under-performance in active labour market policy and education systems,

- challenges arising from new technology such as automation and the related new forms of work,

- social exclusion of marginalised groups including Roma and migrants,

- and low labour mobility.

To address these challenges, the ESF is essentially seeking to address three main goals. The first objective concerns basic financial support for the most deprived persons. The second objective concerns actions promoting employment and social innovation. The third objective is action to protect and develop human health.

\section{Thinking in space according to the ESF Regulation}

Whether we are examining the challenges or the responses to them - in the spirit of the Treaty the question is whether the ESF legislator has spatial visibility, or rather to what extent challenges and answers have a territorial aspect? In other words, whether skills gaps emerge in the same form and whether the same solutions are possible in rural areas as e.g. in industrial areas? Does health protection require the same interventions in rural areas as in urban areas? Overall, is this fund sensitive to territorial specificities? Is there any guarantee element that will ensure the attention of each of the spatial categories listed in the Treaty? Are there any warranty provisions that ensure that the developments result in a reduction in regional disparities rather than an increase? Is ESF Objective alone capable of solving the problem of a territorial unit?

The Community level passes part of the answer to these questions preferably to the Member States for treating them at the level of each operational programme, such as territorial issues. The problem with this attitude is merely that Member States are not obliged to do so, and on the other hand, the sectoral approach is not able to provide the complexity of the conditions necessary to catch up on a given territorial unit with the best intentions. (In practice, it is not uncommon that the real beneficiaries of ESF-type interventions are metropolitan education training organizations who, in administrative sense, perform their mission perfectly - and receive the ESF source - although this has no effect on disadvantaged population as accessibility, the conditions for going to work, which should be provided by another fund, the ERDF, are not yet ensured. ESF resources thus directly enrich entrepreneurs in urban areas, while the regional differences in employment do not decrease, although "the number of clients participating on trainings" can perfectly be accounted for.)

Although the ESF is sensitive to differences and its explicit aim is to mitigate the adverse situation, but unfortunately it is understood only to people - at the level of goals and interventions - without the slightest territorial aspect. If there is no territorial sensitivity at Community level, then there is little chance that, due to for example the country's differentiated territorial features, these territorial differences should decrease significantly.

\section{Complexity}

The sensitivity of the ESF to legislative complexity can be traced in several places in the regulation. On the one hand, it appears in the form of a concrete action to integrate several instruments operating as individual fund into the ESF, and on the other hand - at the intent level - to express the need to cooperate with other funds.: "The ESF+ should in particular ensure complementarities and synergies with the European Regional Development Fund, the Cohesion Fund, the European Maritime and Fisheries Fund, the European Globalisation Adjustment Fund (EGF), the Erasmus Programme and the European Solidarity Corps, the Asylum and Migration 
Fund (AMIF), as well as with the Horizon Europe Programme and the Digital Europe Programme, the Reform Support Programme, including the Reform Delivery Tool. (p. 3.)

Among the programming requirements, the Regulation stipulates as follows: Member States and, where appropriate the Commission, shall foster synergies and ensure coordination, complementarity and coherence between the ESF+ and other Union funds, programmes and instruments both in the planning phase and during implementation. Member States and, where appropriate the Commission, shall optimise mechanisms for coordination." (Part II, Chapter I, Article 7)

In Community regulation, it is practically impossible to find any provisions for the harmonization of the funds. It is a fact that if conditions and mechanisms at Community level are not provided to integrate the fund oriented sectoral development objectives into a complex unit capable to function sufficiently at local or regional level then - with regard to the different requirements of funds - it is almost inconceivable that this could be achieved at Member State level.

The ERDF-ESF separation hits the least-developed regions at least as sensitively as the delimitation of rural areas between the Structural and Cohesion Funds and the EAFRD. (To put it simple, the separation of infrastructure and human development will question the sense or efficiency of many projects - there is no need for a skilled woodcutter, if there is no saw, there is no need for a refurbished school, if there is no competitive training. In fact, the many good EAFRD / LEADER targets of no resources are available and they cannot be financed by ERDFESF funds.)

\section{Resources}

The Regulation intends that Member States shall allocate at least $25 \%$ of their ESF+ resources under shared management to the specific objectives for the social inclusion policy area set out in points (vii) to (xi) of Article 4(1) including the promotion of the socio-economic integration, addressing material deprivation. (Part II Chapter I. Article 7 Paragraph 3)

A certain amount of resources here is not allocated either to a territorial unit or to a territory type, so in principle it may occur that the $25 \%$ will aid the population of urban areas, whereas rural areas, for example, may receive a much worse proportion of dedicated resources.

\section{Indicators}

Compared to the ERDF Regulation, it is certainly a result that the so-called other common performance indicators of the ESF Regulation, include the "number of participants in rural areas". Although the ESF legislator intends to measure neither the impact of territorial units, nor the degree of territorial equalization, but at least in one aspect, the countryside as a territory type, appears in a single indicator.

\section{The major dimensions of the territorial approach, or their absence in legal regulation}

One of the major elements of spatial thinking should be territorial concentration, that is - as stipulated in the Treaty - the emergence of territory types and territorial units and scales that provide effective intervention. Unfortunately, they are both missing and outdated in legal regulatory and regulatory approaches. On the example of rural areas, it was possible to follow up the extent to which the legislator took the provisions of the Treaty into consideration. Another element of the territorial focus would be the definition of a territorial unit corresponding to effective interventions. The territorial scale commonly used in Community legislation is the region, which can be a convenient statistical and accounting unit at Community level, but, as the Barca report has highlighted at Community level almost a decade ago, it is the least suitable territorial level for effective interventions. Thus, in addition to the territory types, the spatial scale of adequate interventions is also missing from the regulation, even at the level of opportunities. If the spatial scale is missing or inappropriate, how can the optimal intervention be associated with it? If there is no optimum intervention, how can it be expected that the primary objective can be to reduce spatial disparities? And if there is no reduction in territorial differences, a similar situation can arise to the depths of the earth, i.e. in the case of tectonic (territorial) tensions that are not visible 
from the surface (above), which may cause heavy earthquakes that may destruct certain areas (territory types) by changing or forever abolishing them from the surface of the earth.

The legislator associates territorial and rural development, which are only a part of the set of sectoral goals, with sub-regional level, which may also be a kind of recognition of regional development aptitude problems.

Another dimension - perhaps the most important - of spatial and rural development is the possibility of complex interventions. The possibility of complexity can be enforced through statutory intervention instruments that can basically be ITI (integrated territorial investment) and CLLD / LEADER (community-led local development). These instruments provide a system of complementary, unified interventions that fit the specificities of a given territorial unit.

The starting point for a developmental philosophy thinking in space and in territorial units would be to support complex regional development, within which, in line with local needs and specificities, the fundamentally sectoral objectives in the provisions on various funds could also appear. Compared to this, the current EU development policy logic assumes that objectives exist at Community level to save every territorial unit, among which only one is the possibility of using instruments involving complex interventions. As regards the source ratios, the minimum ratio of complex territorial and rural development instruments is $6 \%$ to $5 \%$, and sectoral interventions can accordingly receive $94-95 \%$ of resources. Healthy proportions, if not completely inverted, should be at least $2 / 3$ to $1 / 3$ in favour of complex interventions.

Why is this issue of complexity so important, highlighted and particularly worthy of attention? The question can be answered in the form of many-page scientific studies, but it may be enough to start from everyday understandable and pervasive questions of everyday life. What does it lead to when a person is thinking exclusively of food and spending all of his existing resources on it? Or do you think about dressing alone, or is it just putting your self-education on top of everything? Only the consistent harmony of the various activities (sectors) adapted to man and his circumstances can lead to normal functioning and lifestyle. The significantly different ratio of individual activities in everyday life may also mean abnormalities in everyday judgment. This difference is also characterized by the post-2020 development policy of the Community. The lack of complexity, the dominance of various sectoral interests and goals, and the lack of mechanisms ensuring the consistency of the goals go far beyond the normal range. The inefficiency of sectoral development policy to mitigate regional disparities and its extremely low efficiency are clearly demonstrated by indicators showing the absence of convergence of different types of region (e.g. rural areas). However, it is not only this, what is the major issue in a world economy dimension. The question is whether the European economic space will ever become the most competitive region of the world, as set out in Agenda 2000, while addressing existing or growing territorial disparities requires significant Member States resources? To what extent the EU resources not used adequately efficiently are wasted and to what extent are they obstacles to increasing the competitiveness of the European economy?

We also may ask the question why the less effective sectoral development approach is triumphant over the proven more effective spatial development approach at present and seeming rather to win in the future as well?

One of the - presumably decisive - reasons derives from the institutional system of the EU, and more precisely from its structure. The constituents of the development policy divided into directorates and funds have such a distance and the institutional cohesion is so weak that the operation is much more like a fragmented, sovereign system of Greek polis than an integral part of a Fordist plant's oiled parts. Of course, this does not mean that there is no need for Directorates-General, and there would be no need for professionals in the relevant sectors. The well-trained apparatus is even more important if it ever becomes a requirement that their own ideas can be achieved solely with professionals from other sectors. Such a constraint could mean that if only one existed instead of a variety of development funds, a co-operation based on complementarity and respecting each stakeholder's interests would be unavoidable. Such an institutional background could significantly reinforce the application of territorial and rural development methods and the establishment of a healthy proportion of resources allocated to these methods. 
As long as the European Union's organizational structure is unable to modernize itself, Europe has little chance to become the most competitive region of the world thanks to EU development resources. (The survival of the structure can only be strengthened by such Unitarian-type Member States where the sectoral ministries affiliated with their powers and resources are mirroring the EU's organizational structure where territorial and rural development representing some kind of decentralization in the Member State's development policy - are nothing but nuisances for the state's different sectors.)

While law and legal regulation, are incapable of solving basic problems, they can play an extremely important role in fine-tuning, which is also of paramount importance in formulating international documents. It is the decision of the Community legislature on how it intends to make use of compulsory (cogent) and optional (discretionary) provisions, which could - inter alia provide the opportunity to make contents considered to be particularly important (such as the development of rural areas or the application of regional and rural development methods) compulsory. If the overwhelming majority of Community legislation is like a menu to freely choose and pick from, then the very essence of legal regulation - that is its binding force, enforcing power - will be lost. If most of the Community provisions are lex imperfecta, i.e. no sanction is imposed on the breach, then the legal framework will again become unmanageable as the addressees of the law can do anything without any consequences. If the Community legislation is not elaborated with sufficient detail (leaving it to the Member States) and does not include any guarantee provisions that will ensure the functioning of the mechanisms which may result in the achievement of the objectives pursued, the quality of legislation does not necessarily guarantee the achievement of the legislator's objective.

There is no doubt that any or all legislation acceptable to a Member State is a result of a kind of compromise. At the same time, a compromise is meaningless where the realization of the basic goals can be questioned. It is certainly sure that the possibilities provided by the legal framework for the Community legislature offer plenty room for manoeuvring, which, until now, the legislator may not necessarily or perhaps have not used sufficiently.

\section{Final thoughts}

The countryside and rural development seem to be lost in the light of the post-2020 regulatory proposals (the ERDF Regulation does not deal with the countryside at all, the EAGF / EAFRD Regulation basically only interprets rural areas in the context of agricultural activity, the ESF Regulation reacts to only one small section of its problems and opportunities of rural economy and society;

More than four million people are covered by the EAGF / EAFRD in Hungary (rural areas). From this, approx. 5-6\% belong to the circle which, under the title of farmer, qualifies for EMGA-EAFRD support. The agricultural sector alone was never able to make the living of the rural population, just as the whole CAP cannot be responsible for rural development and the fate of the countryside alone.

In a Member State where ERDF or EAGF/EAFRD and EU resources generally do not address the fate of rural population and the Member State cannot influence the fate of the countryside on its own national resources, most of the countryside may be emptied or lived by segregated communities. (The most vulnerable category in Hungary is the category of settlements under 500, where more than a thousand settlements - almost one third of the country's total settlements belong to)

In the absence of the territorial approach and complex solutions applying regional and rural development methods, community development policy cannot be effective unless the development of rural areas is the preferred target of each fund. Complexity and its corresponding proportions are already required at Community level. (From this point of view, the withdrawal of the EAGF/EAFRD from the scope of the common regulation can be considered as a serious step backwards.) 
However, in the absence of these, there is no realistic chance of real reduction of territorial differences between the different types of territories. However, in case of significant territorial differences, it may be difficult for Europe to become the most competitive region in the world.

Similarly, to the Maastricht convergence criteria, it is necessary - and possible - to define cohesion criteria, the meeting of which could ensure a more effective achievement of territorial integration and territorial cohesion.

The contents of the current draft regulations are in no way in line with the objectives set out in the Treaty, and in their present form they are less suitable for fostering real social, economic and territorial cohesion. Reconsidering them would be inevitable. 